\title{
Comparing the Role of Auditory Soothing Effect and Ketamine on Duration of Sedation and Recovery Time in Procedural Sedation and Analgesia (PSA) Among Pediatric Patients in Emergency Department. A Case-Control Comparative Study from a Tertiary Care Setting of LIC
}

Emad Uddin Siddiqui ( $\nabla$ emaduddin.siddiqui@aku.edu )

Aga Khan University Hospital

Ghazala Irfan Kazi

Aga Khan University Hospital

Bushra Qaiser

Aga Khan University Hospital

Raheem Ahmed

Aga Khan University Hospital

Tooba Siddiqui

Aga Khan University Hospital

Research Article

Keywords: Sedation, Auditory Soothing, Ketamine

Posted Date: November 22nd, 2021

DOI: https://doi.org/10.21203/rs.3.rs-1080713/v1

License: (1) (i) This work is licensed under a Creative Commons Attribution 4.0 International License.

Read Full License 


\section{Abstract}

Introduction: Pediatric pain, is a major concern of anxiety and fear during emergency procedures, to alleviate pediatric pain and distress different mode of sedation is required from local, nasal to parental. Appropriate pain relief with adequate sedation and analgesia different drugs are used, however, most have their side effects. Ketamine alone has been used for procedural sedation and analgesia (PSA), but a higher dose may be required to achieve adequate sedation and pain relief, leading to dose-dependent side effects. In this study, we hypothesize that cartoon music or parental/physicians soothing rhymes/sounds during PSA may reduce the dose and frequency of sedative medications, and reduce the duration of sedation and early recovery.

Material and Methods: This is a prospective cross-sectional comparative hospital-based study, we used non-probability consecutive sampling from children below 16 years during 2018-2019, post ethical review board approval from Hospital Ethical Committee (3827-EM-ERC-15 (3827-EM-ERC-15\{Emergency Medicine - Ethical Review Committee\}), who need PSA in ED settings. The PSA was carried by ED physicians who were credentialed for PSA and advanced airway care, while the procedure will be dealt with by another physician from ED or another subspecialty. The study population was divided into two groups, one with Ketamine alone (control group) with 32 patients, while another (case group) with 60 children, who got a low dose of Ketamine along with either of the soothing auditory stimulus, like cartoon music via mobile, parental/physician rhymes during PSA. Data was entered and analyzed using SPSS version-21 Frequency and the percentage was calculated for qualitative variables. Shapiro-Wilk test was applied to check the hypothesis of normality for age (years), sedation, and recovery time, and descriptive statistics such as mean $\pm S D$, median (IQR), maximum and minimum were calculated appropriately. Effect modifiers like age, gender, sedation, and recovery time were addressed through stratification. The poststratification chi-square test was applied by taking $p \leq 0.05$ as significant.

Results: Comparing the two major groups (case and control), there was no statistical difference among age, gender, types of procedures done, and recovery time, however LOS in ED ( $<60$ minutes) and sedation time ( $<30$ minutes) in the case group was statistically better than in control group ( $78 \%$ vs $87 \%$ and $85 \%$ and $78 \%$ respectively). Children with oxygen saturation $\leq 90 \%$ were slightly better in the case group $1.7 \%$ vs $3.1 \%$, similarly $25 \%$ had tachycardia as compared to $28 \%$ in the ketamine-only group. Tachypnea was observed in $21.7 \%$ vs $28 \%$ among the case and control groups. Importantly ketamine repeat dose was observed in $34.4 \%$ among control (ketamine only) group and only 21.7 need repeated dose in the case group.

Discussion: The goal of PSA was to relieve anxiety and fear of pain during the procedure in chaotic EDs. This will help in gaining child cooperation and parents' satisfaction along with reduced drug dose, minimizing LOS, speedy recovery time, and lessening the anticipated drug-related complications. The significant finding observed was the total sedation time and LOS in ED which was significantly better in the control group. Younger children were better soothed by parental voice (rhymes) as compared to other soothing methods examined, similarly lesser drop in oxygen saturation, minimal tachycardia or 
tachypnea were observed and fewer repeat doses of Ketamine was used as compared to the control group. Music during PSA demonstrates a reduction in patient anxiety, however, the dose and frequency of sedation required didn't show any such reduced medications.

Conclusion: In conclusion, listening to cartoon music or parental sound/rhymes has no significant effect on the hemodynamic variables or the drug consumption among pediatric patients during PSA. By considering the reported beneficial results of previous studies, listening to music can be accepted as an adjunct non-pharmacological method for sedation.

\section{Introduction}

Pain is the major concern that leads to anxiety and fear among children presenting to pediatric emergencies. They are unable to appreciate the exact location, and pain management is the topmost priority in an emergency. Other than medical or surgical emergencies with pain there are some other aspects of trauma pain or pain associated with procedures like laceration repair, fracture reduction, lumbar puncture, and burn management, etc. Foreign body removal, chest tube placement, cardioversion, abscess drainage, and other life-saving invasive procedure like central line, arterial line, endoscopy, and imaging studies were a few other procedures to alleviate pain and need sedation. $(1,21)$ Hence anxiety and pain relief during procedures in pediatric emergency medicine (PEM), with appropriate sedation and adequate analgesia is required with the agent that will not only have a rapid onset with immediate induction, minimal side effect and lesser complications followed by smooth and speedy recovery to minimize drug associate side effect (like cardiovascular and respiratory function, vomiting, etc.), length of ED stay, early recovery time but will also cater the parental concern and frustration of drug used. (2)

Most available drugs used are good sedative, anxiolytic, and pain alleviated properties, however, they are not free from side effects. Even a combination of drugs with different and antagonizing effects is not safe, Ketamine and Propofol have balancing effects on one another but both cause respiratory compromise, furthermore, a combination of drugs may aggravate the duration and depth of sedation (6, $7)$, even with minimal desire dose to achieve a controlled state of semi-consciousness with intact airway reflexes and patency, this may aggravate the health care resource utilization, increase recovery time, length of ED stay (LOS), cost, parental dissatisfaction, and burden on ED turn over. $(3,4,8)$

Ketamine alone has been used for procedural sedation and analgesia (PSA), but a higher dose may be required to achieve adequate sedation and pain relief, leading to dose-dependent side effects like arrhythmias, high or low blood pressure or bradycardia, cardiac and respiratory arrest, or apnea, increased laryngeal, and tracheal secretions, laryngospasm other than anxiety, confusion, depression, disorientation, dysphoria, dissociative state hallucinations, flashbacks, unusual thoughts, extreme fear, excitement, and irrational behavior and insomnia. (5)

In this study, we hypothesize that cartoon music or parental/physicians soothing rhymes/sounds during PSA may reduce the dose and frequency of sedative medications, increase depth and duration of sedation. We try to evaluate the role of ketamine at minimal dose along with auditory stimulation to a 
child undergoing PSA to observe the impact on the reduction of procedural and recovery time, length of ED stay, and any impact on vitals during PSA or the need for repeat dose and to compare it with other group undergone PSA with higher (single or repeat) dose Ketamine among children for diagnostic or therapeutic procedures performed in ED from the low-income setting of a tertiary care teaching hospital.

\section{Materials And Methods}

This is a prospective cross-sectional comparative hospital-based study, we use non-probability consecutive sampling from children below 16 years during 2018-2019, who need PSA in ED settings, post ethical review board approval from Hospital Ethical Committee (3827-EM-ERC-15\{Emergency Medicine Ethical Review Committee\}), and informed consent from parents, as per hospital policy both for sedation and procedure. Patients allergic to Ketamine or its constituent, hemodynamic instability or children with a score of $\geq 3$ as per American Society of Anesthesiologist classification, Mallampatti score of class $\geq 2$, Modified Alderate score $\leq 6$, or hearing defect were excluded from the study. We use a convenient sampling technique, a similar study conducted focusing on the use of Ketamine and Propofol among PSA in the same study center with a study population of 179 , the margin of error of $6 \%$, confidence interval of $90 \%$, the sample size as calculated using Raosoft software was 92. (7)

The PSA will be carried by ED physicians who were credentialed for PSA and advanced airway care, while the procedure will be dealt with by another physician from ED or another subspecialty. All cases must have at least 4-6 hours of the fast of either gender from age $>6$ months to 15 years, without any premedication.

We divide the study population into two groups, one is Ketamine alone (control group) with 32 patients, while another (case group) with 60 cases who were managed with a low dose of Ketamine along with either of the soothing auditory stimulus. These are either No soothing effect rather disturbing sound of busy ED, Parental auditory sound (talking or rhymes), Physicians auditory soothing sounds or Cartoon auditory sounds (music). The two groups were compared with a ratio of 2:1, 60 were in the case group and 32 children were in control. (MUSIC VIA MOBILE, CARTOON MUSIC) OR PARENTAL RHYMES AT THE TIME OF PSA.

Ketamine as the sedative drug was used @ $0.5 \mathrm{mg} / \mathrm{kg}$ IV as the initial dose in both groups, however, a repeat dose may be used where needed @ $0.5 \mathrm{mg} / \mathrm{kg}$ (second or third dose) with a cumulative dose of $1.5-2.0 \mathrm{mg} / \mathrm{kg}$ were given as per physician advice when necessary in cases when tachycardia observed and/or observed bodily movement/awakening child. Before the start of the PSA, children remain in their parental lap and relaxed with video, rhymes, or stories, and their beds were assigned in a comfortable area with normal ED surrounding noise. Parents accompany the child in the procedure room to support the sedation and research team with the child's favorite video/audio, rhymes, song, and story by parents in the case group. Control (ketamine only) group parents were asked to stay in the waiting area.

There was no subjective observation recorded for this study, we document vitals, complications, LOS, duration of sedation and recovery time, etc. Facemask, oxygen, and crash cart were available all the time 
during the procedure and the patient remain on cardiac monitor throughout the process till full recovery.

The data were collected by the research officer on a predesigned form, another official form was also filled as per the hospital sedation policy which includes demographic time out, procedure start and end time, doses administered, total sedation time (from initial sedation injection to spontaneous eye-opening), recovery time (time passed from end of the procedure to awakening), Length stay (LOS) in ED (time from complete recovery to discharge), vital signs and any complications like bradycardia, hypoxia(oxygen saturation $<93 \%$ ), apnea, etc. and interventions are taken. Discharge criteria as per hospital policy were when a child can maintain his airway, fully awake and able to swallow clear liquids and achieve a presedation level of responsiveness.

Data will be entered and analyzed using SPSS version-21 (IBM Corp. Released 2012. IBM SPSS Statistics for Windows, Version 21.0. Armonk, NY: IBM Corp). Frequency and percentage were calculated for qualitative variables like gender and complications. Shapiro-Wilk tests were applied to check the hypothesis of normality for age (years), sedation, and recovery time. and descriptive statistics such as mean $\pm S D$, median (IQR), maximum and minimum were calculated appropriately. Effect modifiers like age, gender, sedation, and recovery time were addressed through stratification. The post-stratification chisquare test was applied by taking $p \leq 0.05$ as significant.

\section{Provision of Data Availability:}

We make sure the availability of data as and when required by the editor and Corresponding author will be responsible to provide this data.

\section{Results}

In this comparative study, ninety-two cases were enrolled, PSA with ketamine in the control group includes sixty children, while the case group includes thirty-two children for whom a low dose of ketamine was introduced along with soothing effects. The soothing effects were further divided into four groups from no soothing effect rather disturbing sound of busy ED, Parental auditory sound (talking or rhymes), Physicians auditory soothing sounds, or Cartoon auditory sounds (music). The characteristic of both group for different variables is elaborated in Table I, while Table II further elaborate the cases cluster into four subgroups.

Comparing the two major groups (case and control), there was no statistical difference among age, gender, types of procedures done, and recovery time, however, LOS in ED ( $<60$ minutes) and sedation time ( $<30$ minutes) in the case group was statistically better than in control group ( $78 \%$ vs $87 \%$ and $85 \%$ and $78 \%$ respectively). Table I.

Table III, further elaborates the case group into four components and we found most cases who experienced auditory soothing by their parents (mother or father) during PSA i.e. 36 (60\%) cases, and 21 
(58\%) children were below two years of age. Considering the LOS of $<30$ minutes, in the case group there were32 (53\%) children.

Figures I, compare case and control groups in terms of ketamine dosage along with soothing effects.

Focusing on the vitals children's drops of oxygen saturation $\leq 90 \%$ were slightly better in the case group $1.7 \%$ vs $3.1 \%$, similarly $25 \%$ had tachycardia as compared to $28 \%$ in the ketamine only group. Tachypnea was observed in $21.7 \%$ vs $28 \%$ among the case and control groups. Importantly ketamine repeat dose was observed in $34.4 \%$ among control (ketamine only) group and only 21.7 need repeated dose in the case group.

\section{Discussion}

The goal of PSA among pediatric cases is to relieve anxiety and fear of pain during the painful procedure in chaotic EDs. This will help in gaining child cooperation and parents' satisfaction along with reduced drug dose, minimizing LOS, speedy recovery time, etc, and minimizing the anticipated drug-related complications. There are few non-pharmacological methods used in literature like listening to music, but we introduce two more interventions like rhymes by parents, cartoon voice, physicians soothing sound and without auditory sound (rather disturbing sound of Ed surroundings).

The significant finding observed from this study was the total sedation time and LOS in ED which was significantly better than in the control group. Younger children were better soothed by parental voice (rhymes) as compared to other soothing methods examined, similarly lesser drop in oxygen saturation, minimal tachycardia or tachypnea were observed and fewer repeat doses of Ketamine was used as compared to the control group. However meta-analysis by Victor Fu. et. al didn't observe any significant effect of music on LOS, but the cases included were all admitted to the hospital who had undergone major surgical procedures in OR. (25)

The healing and soothing effects of music have been known for a long, this is an important, cheaper, noninvasive method with no side effects. Music therapy has been used in past to alleviate pain and anxiety in patients undergoing painful procedures. $(9,10)$ However, literature has a mixture of pieces of evidence to favor or not on the use of music or other soothing effects during a painful procedure. Listening to music or parental rhymes during painful procedures in ED may reduce recovery time, LOS in ED, sedation time, or speedy recovery and may reduce the need for higher or repeated doses of sedation. $(11,25)$ However, few others didn't support the role of auditory stimuli. $(12,13)$ There has been much debate on the role of music and its beneficial role in a pediatric patient undergoing PSA for a painful procedure, but comparing this with parental soothing role via child favorite rhymes or parental talking to child during PSA has not been identified from the literature. (14)

Children are more frustrated and sensitive to stressful ED environments and procedures, hence parental support and/or music during the procedure and may alleviate their anxiety and stress. This has been observed that the dose of anesthetic drugs has been reduced, with greater hemodynamic stability and 
shortened recovery time. (15) The use of music or soothing sounds decreases the sedative dose requirements as compared to the control group. (16)A meta-analysis by Victor Fu. et. al. observed that pre-procedure music significantly reduced sedative requirement, whilst achieving some sedation levels. (25).

Music during PSA demonstrates a reduction in patient anxiety, however, the dose and frequency of sedation required didn't show any such reduced medications. However, we observed contradictory results with more cases who need a single Ketamine dose among those who were sooth as compared to the control group. (17). Recovery time was much lesser in the case group, this may be due to minimal ketamine dose and auditory soothing effects, similar results by Ozkalayci. 0 et.al. also observed a shortened recovery time post-PSA. $(14,25)$

Patient anxiety and fear of painful procedures are major concerns among children and parents, which is directly related to altered vitals, LOS, depth of sedation, and recovery time, hence to minimize the cost and increase patient turnover in ED, soothing by any means like cartoon music, rhymes, etc. may be used during the painful procedure to minimize the dose of sedative medications and its related complications. However few studies didn't support hemodynamic variability. $(14,18)$. The beneficial effect of music/auditory soothing was evidenced in the literature on different vitals variables like blood pressure, heart rate, respiratory rate, and oxygen saturations, and variation was documented but is not statistically significant. $(19,20)$.

There was an average of 3.9\% incidence of airway and respiratory adverse events with the use of ketamine during PSA as evident from a meta-analysis of 8,282 pediatric cases which was pooled from 32 studies, identified an increased risk of side effects with high IV doses of ketamine. (22).

Some of the studies identified oxygen desaturation, airway obstruction, and apnea as common adverse events, with around 2.3\% incidence when delivered by ED physicians. (23) Similarly we found $3.1 \%$ cases with ketamine alone had an oxygen saturation of drop to $<90 \%$, however in cases with low dose ketamine along with auditory soothing effects this was reduced to $1.7 \%$, though statistically not significant.

We analyze soothing with different sounds like cartoon music, physicians and parental voice as rhymes and no soothing effect rather busy ED noises like voice pager, children cry, staff and physicians voice and voice of monitor alarms and all these sounds may lead to additional stress and anxiety to children especially when they are without parents. (24) Comparing the effect of music on sedation has been studied, however, parental rhymes and physicians soothing voices were not tested and compared with cartoon-related music and no auditory sound. This study is to my knowledge is first of its kind to compare.

\section{Limitation:}


There are multiple limitations in this study like depth of sedation was not monitored, hearing check and cognitive test before the study was also not evaluated, type, volume, and duration of music was not standardized, moreover, the headphone was not used during the process, and music was managed via mobile phone, similarly, parental rhymes was also not standardized.

\section{Conclusion}

In conclusion, listening to cartoon music or parental sound/rhymes has no significant effect on the hemodynamic variables or the drug consumption of the pediatric patients during PSA. By considering the reported beneficial results of previous studies, listening to music can be accepted as an adjunct nonpharmacological method for sedation. However, we believe that the patient should be targeted to a low level of sedation to increase the analgesic and anxiolytic effects of music in sedation. Similar studies in the future may consider the limitations of our study and target an appropriate sedation level for the patients.

\section{Declarations}

This is to confirm that all methods performed during data collection was in accordance with the guidelines and regulations as per the international standards of hospital policy and Hospital Ethical Review Committee (3827-EM-ERC-15 \{Emergency Medicine - Ethical Review Committee\}).

\section{Consent for Publication:}

We provide Consent for publication to the said journal.

\section{Competing Interests:}

I declare that, there is no competing financial and non-financial interests of any of the author listed nor the institution as defined by BMC.

\section{References}

1. Chiaretto A, Ruggiero A, Barbi E, Pierri F, Maurizi P, Fantacci C, et al. Comparison of propofol versus propofol-ketamine combination in pediatric oncologic procedures performed by nonanesthesiologists. Pediatr Blood Cancer. 2011;57(7):1163-7.

2. Alletag MJ, Auerbach MA, Baum CR. Ketamine, propofol, and ketofol use for pediatric sedation. Pediatr Emerg Care. 2012;28(12):1391-5; quiz 6-8.

3. Coulter FL, Hannam JA, Anderson BJ. Ketofol dosing simulations for procedural sedation. Pediatr Emerg Care. 2014;30(9):621-30. 
4. Smischney NJ, Hoskote SS, Gallo de Moraes A, Racedo Africano CJ, Carrera PM, Tedja R, et al. Ketamine/propofol admixture (ketofol) at an induction in the critically ill against etomidate (KEEP PACE trial): study protocol for a randomized controlled trial. Trials. 2015;16:177.

5. Steven B. Rosenbaum; Vikas Gupta; Jorge L. Palacios. Ketamine. Downloaded on January 22, 2021. https://www.ncbi.nlm.nih.gov/books/NBK470357/

6. Andolfatto G, Abu-Laban RB, Zed PJ, Staniforth SM, Stackhouse S, Moadebi S, et al. Ketaminepropofol combination (ketofol) versus propofol alone for emergency department procedural sedation and analgesia: a randomized double-blind trial. Ann Emerg Med. 2012;59(6):504-12 e1-2.

7. Andolfatto G, Willman E. A prospective case series of pediatric procedural sedation and analgesia in the emergency department using a single-syringe ketamine-propofol combination (ketofol). Acad Emerg Med. 2010;17(2):194-201.

8. Qaiser B, Siddiqui E. Outcome and Safety of Ketamine and Propofol use in Procedural Sedation and Analgesia (PSA) among Pediatric Patients in Emergency Department of a Tertiary care setting. <background-color:\#C09200;buvertical-align:baseline;>Unpublished Data</backgroundcolor:\#C09200;buvertical-align:baseline;><buvertical-align:baseline;>.</buvertical-align:baseline;>

9. Nadiya Ö, Zeynep KÖ, Sevban A, et al: Effect of music on postoperative pain and physiologic parameters of patients after open-heart surgery. Pain Manag Nurs 2013; 14: 20-28.

10. Premendran B, Dongre H, Domkondwar U: The efficacy of music in lowering intraoperative sedation requirement and recall of intraoperative process. IOSR J Pharm 2012; 2: 569-578.

11. Tsuchiya M, Asada A, Ryo K, et al: Relaxing intraoperative natural sound blunt hemodynamic change at the emergence from Propofol general anesthesia and increases the acceptability of anesthesia to the patient. Acta Anaesthesiol Scand 2003; 47: 939-943.

12. Van der Laan WH, van Leeuwen BL, Sebel PS, et al: Therapeutic suggestion does not affect postoperative morphine requirements. Anesth Analg 1996; 82: 148-152.

13. Migneault B, Girard F, Albert C, et al: The effect of music on the neuro-hormonal stress response to surgery under general anesthesia. Anesth Analg 2004; 98: 527-532.

14. Ozkalayci. O, Araz. C, Cehreli. C. B, Trail. R. E, Kayhan. Z. Effects of music on sedation depth and sedative use during pediatric dental procedures. Journal of Clinical Anesthesia 2016; 34:647-653. http://dx.doi.org/10.1016/j.jclinane.2016.07.001

15. Bruhn J, Bouillon TW, Radulescu L. Correlation of approximate entropy, bi-spectral index and spectral edge frequency 95 (SEF95) with clinical signs of "anesthetic depth" during co-administration of Propofol and remifentanil. Anesthesiology 2003; 98: 621-627.

16. Bansal. P, Kharod. U, Patel. P, Sanwatsarkar. S, Patel. H, Kamat. H. The Effect of Music Therapy on Sedative Requirements and Haemo-dynamic Parameters in patients under Spinal Anesthesia; A Prospective Study. Journal of Clinical and Diagnostic Research. 2010 August;(4): 2782-89

17. Weeks. BP, Nilsson U. Music interventions in patients during coronary angiographic procedures: a randomized controlled study of the effect on patient's anxiety and well-being. Eur J Cardiovasc Nurs $2011 ; 10: 88-93$. 
18. Kalyani P N, Poonam G G, Shalini K T. Impact of intraoperative music therapy on the anesthetic requirement and stress response in laparoscopic surgeries under general anesthesia. Ain-Shams $\mathrm{J}$ Anesthesiol. 2015;8:580-584

19. Jayaraman. L, Shikha. S, Sethi N, Sood. J, Kumra. V.P. Does intraoperative music therapy or positive therapeutic suggestions during general anesthesia affect the postoperative outcome? A double-blind randomized controlled trial. Indian J Anaesth. 2006; 50 (4):258-261.

20. Binns-Turner PG, Wilson LL, Pryor ER, et al. Perioperative music and its effects on anxiety, hemodynamics, and pain in women undergoing mastectomy. AANA J. 2011; 79 (4):21-27.

21. Mason. K. P. Challenges in pediatric procedural sedation: political, economic, and clinical aspects. British Journal of Anesthesia 113 (S2): ii48-ii62 (2014) doi:10.1093/bja/aeu387

22. Green SM, Roback MG, Krauss B, et al. Predictors of the airway and respiratory adverse events with ketamine sedation in the emergency department: an individual patient data meta-analysis of 8,282 children. Ann Emerg Med 2009; 54: 158-68 e1-4

23. Mallory MD, Baxter AL, Yanosky DJ, Cravero JP, Pediatric Sedation Research C. Emergency physicianadministered Propofol sedation: a report on 25,433 sedations from the pediatric sedation research consortium. Ann Emerg Med 2011; 57: 462-8 e1

24. Tsuchiya M, Asada A, Ryo K, et al: Relaxing intraoperative natural sound blunts hemodynamic change at the emergence from Propofol general anesthesia and increases the acceptability of anesthesia to the patient. Acta Anaesthesiol Scand 2003; 47: 939-943

25. Fu. V.X, Oomens. Y. P, Klimek. M, Verhofstad. M. H, Jeekel. J. The Effect of Perioperative Music on Medication Requirement and Hospital Length of Stay. A Meta-analysis. Ann Surg. December 2020;272 (6):961-972

\section{Tables}


Table I

Demography and Frequency of all cases.

\begin{tabular}{|c|c|}
\hline Age in Years & Frequency [\%] \\
\hline$<2$ years & 49 [54.45] \\
\hline $2-3$ years & $33[35.9 \%]$ \\
\hline 4-5 years & $10[10.9 \%]$ \\
\hline \multicolumn{2}{|l|}{ Gender } \\
\hline Male & $50[54.3 \%]$ \\
\hline Female & $42[45.7 \%]$ \\
\hline \multicolumn{2}{|l|}{ Procedure } \\
\hline Lip Laceration & $11[12 \%]$ \\
\hline Cheek Laceration & $12[13 \%]$ \\
\hline Chin Laceration & $15[16.3 \%]$ \\
\hline Eyebrow Laceration & $20[21.7 \%]$ \\
\hline Forehead Laceration & 19 [20.7\%] \\
\hline Scalp Laceration & $6[6.5 \%]$ \\
\hline Finger Laceration & $7[7.6 \%]$ \\
\hline Lumbar puncture & $2[2.2 \%]$ \\
\hline Fracture reduction & $0[0 \%]$ \\
\hline \multicolumn{2}{|l|}{ LOS in (Min) } \\
\hline$<30$ minutes & $17[18.5 \%]$ \\
\hline 30-60 minutes & $58[63 \%]$ \\
\hline$>60$ minutes & $17[18.5 \%]$ \\
\hline \multicolumn{2}{|l|}{ Sedation time in (Min) } \\
\hline$<15$ minutes & $35[38 \%]$ \\
\hline 16 - 30 minutes & $41[44.6 \%]$ \\
\hline 31 - 45 minutes & $16[17.4 \%]$ \\
\hline \multicolumn{2}{|l|}{ Recovery time in (min) } \\
\hline$<10$ minutes & $45[48.9 \%]$ \\
\hline
\end{tabular}




\begin{tabular}{ll}
\hline 10 - 20 minutes & $24[26.1 \%]$ \\
\hline 20 - 30 minutes & $15[16.3 \%]$ \\
\hline 13 - 40 minutes & $8[8.7 \%]$ \\
\hline Complications & \\
\hline$<93 \%$ SPO2 & $2[2.2 \%]$ \\
\hline Tachycardia according to age (beats/min) & $24[26.1 \%]$ \\
\hline Bradycardia according to age (beats/min) & $4[4.3 \%]$ \\
\hline Stridor/cough & $3[3.3 \%]$ \\
\hline Hypotension according to age in (mmHg) & $20[21.7 \%]$ \\
\hline Tachypnea according to age (breaths/min) & $22[23.9 \%]$ \\
\hline Ketamine doses & \\
\hline Single-dose & $68[73.9 \%]$ \\
\hline Repeat dose & $24[26.1 \%]$ \\
\hline Ketamine repeat dose & \\
\hline 1.0 mg/kg & $67[72.8 \%]$ \\
\hline 0.5 mg/kg & $25[27.2 \%]$ \\
\hline Outcome & $60[65.2 \%]$ \\
\hline Ketamine along with auditory soothing & $32[34.8 \%]$ \\
\hline Sedation with Ketamine & \\
\hline
\end{tabular}


Table II

Frequency of both groups (case and control)

\begin{tabular}{lllll} 
Clinical Characteristics & $\begin{array}{l}\text { Ketamine along } \\
\text { with } \\
\text { auditory soothing }\end{array}$ & $\begin{array}{l}\text { Sedation } \\
\text { with } \\
\text { Ketamine }\end{array}$ & Total & P-value \\
& {$[\mathrm{n}=60]$} & {$[\mathrm{n}=32]$} & {$[\mathrm{n}=92]$} & \\
\hline Age in Years & $31[51.7 \%]$ & $18[56.3 \%]$ & $\begin{array}{l}49 \\
{[53.3 \%]}\end{array}$ & 0.781 \\
\hline$<2$ years & $23[38.3 \%]$ & $10[31.3 \%]$ & $\begin{array}{l}33 \\
{[35.9 \%]}\end{array}$ \\
\hline 2-3 years & $6[10 \%]$ & $4[12.5 \%]$ & $\begin{array}{l}10 \\
{[10.9 \%]}\end{array}$ \\
\hline $4-5$ years & & & &
\end{tabular}

Gender

Male

$33[55 \%]$

$17[53.1 \%]$

50

[54.3\%]

0.863

Female

27 [45\%]

$15[46.9 \%]$

42

[45.7\%]

Procedure

Lip Laceration

$6[10 \%]$

5 [15.6\%]

$11[12 \%]$

0.6666

Cheek Laceration

8 [13.3\%]

4 [12.5\%]

$12[13 \%]$

Chin Laceration

12 [20\%]

3 [9.4\%]

15

[16.3\%]

Eyebrow Laceration

12 [20\%]

8 [25\%]

20

[21.7\%]

Forehead Laceration

13 [21.7\%]

6 [18.8\%]

19

[20.7\%]

Scalp Laceration

5 [8.3\%]

1 [3.1\%]

6 [6.5\%]

Finger Laceration

3 [5\%]

4 [12.5\%]

7 [7.6\%]

Lumbar puncture

1 [1.7\%]

1 [3.1\%]

2 [2.2\%]

Fracture reduction

0 [0\%]

0 [0\%]

0 [0\%]

LOS in (Min)

$<30$ minutes

10 [16.7\%]

7 [21.9\%]

17

[18.5\%]

0.052

30-60 minutes

37 [61.7\%]

21 [65.6\%]

58 [63\%] 
$>60$ minutes

$13[21.7 \%]$

4 [12.5\%]

17

[18.5\%]

Sedation time in (Min)

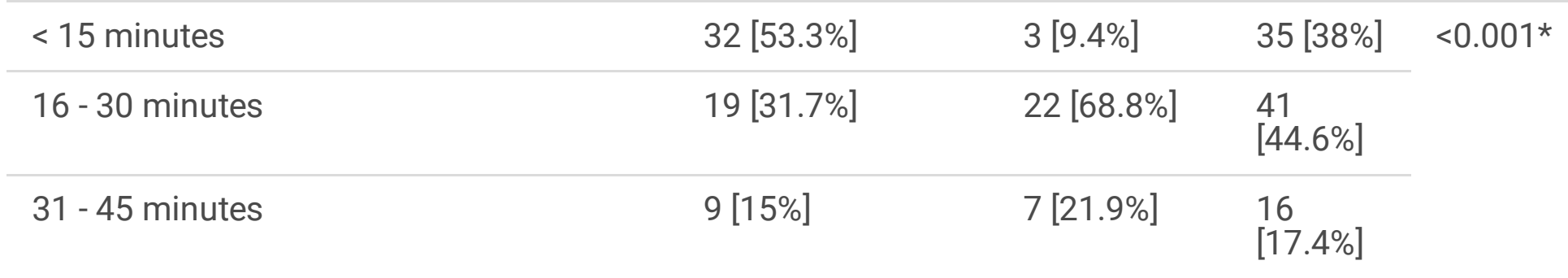

Recovery time in (min)

\begin{tabular}{|c|c|c|c|c|}
\hline$<10$ minutes & 29 [48.3\%] & 16 [50\%] & $\begin{array}{l}45 \\
{[48.9 \%]}\end{array}$ & 0.134 \\
\hline $10-20$ minutes & 13 [21.7\%] & 11 [34.4\%] & $\begin{array}{l}24 \\
{[26.1 \%]}\end{array}$ & \\
\hline 20 - 30 minutes & 10 [16.7\%] & 5 [15.6\%] & $\begin{array}{l}15 \\
{[16.3 \%]}\end{array}$ & \\
\hline 13 - 40 minutes & 8 [13.3\%] & $0[0 \%]$ & 8 [8.7\%] & \\
\hline \multicolumn{5}{|l|}{$<93 \%$ SPO2 } \\
\hline NO & 59 [98.3\%] & 31 [96.9\%] & $\begin{array}{l}90 \\
{[97.8 \%]}\end{array}$ & \multirow[t]{2}{*}{0.648} \\
\hline YES & 1 [1.7\%] & 1 [3.1\%] & 2 [2.2\%] & \\
\hline \multicolumn{5}{|c|}{$\begin{array}{l}\text { TACHYCARDIA ACCORDING TO AGE } \\
\text { (beats/min) }\end{array}$} \\
\hline NO & 45 [75\%] & 23 [71.9\%] & $\begin{array}{l}68 \\
{[73.9 \%]}\end{array}$ & \multirow[t]{2}{*}{0.745} \\
\hline YES & 15 [25\%] & 9 [28.1\%] & $\begin{array}{l}24 \\
{[26.1 \%]}\end{array}$ & \\
\hline
\end{tabular}

BRADYCARDIA ACCORDING TO AGE (beats/min)

\begin{tabular}{lllll} 
NO & $58[96.7 \%]$ & $30[93.8 \%]$ & $\begin{array}{l}88 \\
{[95.7 \%]}\end{array}$ & 0.514 \\
\cline { 1 - 2 } YES & $2[3.3 \%]$ & $2[6.3 \%]$ & $4[4.3 \%]$ & \\
\cline { 1 - 3 } Stridor/Cough & & & & \\
NO & $57[95 \%]$ & $32[100 \%]$ & $\begin{array}{l}89 \\
{[96.7 \%]}\end{array}$ & 0.198 \\
YES & $3[5 \%]$ & $0[0 \%]$ & $3[3.3 \%]$ &
\end{tabular}

HYPOTENSION ACCORDING TO AGE IN $\mathrm{mmHg}$ 


\begin{tabular}{|c|c|c|c|c|}
\hline NO & 50 [83.3\%] & 22 [68.8\%] & $\begin{array}{l}72 \\
{[78.3 \%]}\end{array}$ & 0.106 \\
\hline YES & 10 [16.7\%] & 10 [31.3\%] & $\begin{array}{l}20 \\
{[21.7 \%]}\end{array}$ & \\
\hline \multicolumn{5}{|c|}{$\begin{array}{l}\text { TACYPNEA ACCORDING TO AGE } \\
\text { (breaths/min) }\end{array}$} \\
\hline NO & 47 [78.3\%] & 23 [71.9\%] & $\begin{array}{l}70 \\
{[76.1 \%]}\end{array}$ & \multirow[t]{2}{*}{0.489} \\
\hline YES & 13 [21.7\%] & 9 [28.1\%] & $\begin{array}{l}22 \\
{[23.9 \%]}\end{array}$ & \\
\hline \multicolumn{5}{|c|}{ Ketamine doses } \\
\hline Single dose & 47 [78.3\%] & 21 [65.6\%] & $\begin{array}{l}68 \\
{[73.9 \%]}\end{array}$ & \multirow[t]{2}{*}{0.186} \\
\hline Repeat dose & 13 [21.7\%] & 11 [34.4\%] & $\begin{array}{l}24 \\
{[26.1 \%]}\end{array}$ & \\
\hline \multicolumn{5}{|c|}{ Ketamine repeat dose } \\
\hline $1.0 \mathrm{mg} / \mathrm{kg}$ & 47 [78.3\%] & 20 [62.5\%] & $\begin{array}{l}67 \\
{[72.8 \%]}\end{array}$ & \multirow[t]{2}{*}{0.104} \\
\hline $0.5 \mathrm{mg} / \mathrm{kg}$ & 13 [21.7\%] & 12 [37.5\%] & $\begin{array}{l}25 \\
{[27.2 \%]}\end{array}$ & \\
\hline
\end{tabular}

Table III

Description of Case group 
Variable

Attribute
No Auditory Soothing effect (rather disturbing ED sounds)
Parents

Auditory Sounds

(talking or rhymes)
Physicians auditory

Sounds
Cartoon

auditory

Sounds

(child

choice)

Total

value

\section{Age in Years}

$<2$ years

2 [28.6\%]

21 [58.3\%]

5 [50\%]

3 [42.9\%]

31

[51.7\%]

0.877

2-3 years

4 [57.1\%]

12 [33.3\%]

4 [40\%]

3 [42.9\%]

23

[38.3\%]

4-5 years

1 [14.3\%]

3 [8.3\%]

1 [10\%]

1 [14.3\%]

6 [10\%]

\section{Gender}

Male

4 [57.1\%]

23 [63.9\%]

3 [30\%]

3 [42.9\%]

33

[55\%]

Female

3 [42.9\%]

$13[36.1 \%]$

7 [70\%]

4 [57.1\%]

27

[45\%]

\section{Duration of}

Hospital Stay.

$<30$ minutes $\quad 0[0 \%]$

8 [22.2\%]

2 [20\%]

$0[0 \%]$

10

[16.7\%]

0.111

30-60 minutes 5 [71.4\%]

$24[66.7 \%]$

$5[50 \%]$

3 [42.9\%]

37

[61.7\%]

$>60$ minutes

2 [28.6\%]

$4[11.1 \%]$

$3[30 \%]$

$4[57.1 \%]$

13

[21.7\%]

\section{Sedation time}

$<15$ minutes

2 [28.6\%]

$23[63.9 \%]$

5 [50\%]

2 [28.6\%]

32

[53.3\%]

0.186

$16-30$

minutes

$31-45$

minutes

3 [42.9\%]

$10[27.8 \%]$

$4[40 \%]$

2 [28.6\%]

19

[31.7\%]

Recovery time

$<10$ minutes

$10-20$

minutes

$20-30$

minutes
$3[8.3 \%]$

2 [28.6\%]

3 [42.9\%]

$17[47.2 \%] \quad 5[50 \%]$

4 [57.1\%]

29

[48.3\%]

9 [15\%]

0.25

(111 
$13-40$

minutes
1 [14.3\%]

5 [13.9\%]

2 [20\%]

0 [0\%]

8

[13.3\%]

\section{Tachycardia}

\begin{tabular}{|c|c|c|c|c|c|}
\hline No & 5 [71.4\%] & 27 [75\%] & 8 [80\%] & 5 [71.4\%] & $\begin{array}{l}45 \\
{[75 \%]}\end{array}$ \\
\hline Yes & 2 [28.6\%] & 9 [25\%] & 2 [20\%] & 2 [28.6\%] & $\begin{array}{l}15 \\
{[25 \%]}\end{array}$ \\
\hline
\end{tabular}

\section{Bradycardia}

No

6 [85.7\%]

35 [97.2\%]

10 [100\%] 7 [100\%]

58

[96.7\%]

0.358

Yes

1 [14.3\%]

1 [2.8\%]

0 [0\%]

$0[0 \%]$

2

[3.3\%]

\section{Stridor/Cough}

No

7 [100\%]

35 [97.2\%]

9 [90\%]

6 [85.7\%]

57

[95\%]

Yes

0 [0\%]

1 [2.8\%]

1 [10\%]

1 [14.3\%]

3 [5\%]

Hypotension

$\begin{array}{llllll}\text { No } & 5[71.4 \%] & 31[86.1 \%] & 7[70 \%] & 7[100 \%] & \begin{array}{l}50 \\ {[83.3 \%]}\end{array} \\ \text { Yes } & 2[28.6 \%] & 5[13.9 \%] & 3[30 \%] & 0[0 \%] & 10 \\ & & & & {[16.7 \%]}\end{array}$

\section{Tachypnea}

\begin{tabular}{|c|c|c|c|c|c|}
\hline No & 5 [71.4\%] & 28 [77.8\%] & 9 [90\%] & 5 [71.4\%] & $\begin{array}{l}47 \\
{[78.3 \%]}\end{array}$ \\
\hline Yes & 2 [28.6\%] & 8 [22.2\%] & 1 [10\%] & 2 [28.6\%] & $\begin{array}{l}13 \\
{[21.7 \%]}\end{array}$ \\
\hline
\end{tabular}

\section{Ketamine}

repeated

\begin{tabular}{lllllll}
$1.0 \mathrm{mg} / \mathrm{kg}$ & $5[71.4 \%]$ & $28[77.8 \%]$ & $8[80 \%]$ & $6[85.7 \%]$ & $\begin{array}{l}47 \\
{[78.3 \%]}\end{array}$ & 0.444 \\
\cline { 1 - 4 } & $2[28.6 \%]$ & $8[22.2 \%]$ & $2[20 \%]$ & $1[14.3 \%]$ & $\begin{array}{l}13 \\
{[21.7 \%]}\end{array}$ \\
\hline
\end{tabular}

\section{Ketamine}

doses

$\begin{array}{llllll}\text { Single dose } & 5[71.4 \%] & 28[77.8 \%] & 8[80 \%] & 6[85.7 \%] & 47 \\ {[78.3 \%]} & 0.931\end{array}$




$\begin{array}{lllll}\text { Repeat dose } \quad 2[28.6 \%] & 8[22.2 \%] & 2[20 \%] & 1[14.3 \%] & 13 \\ {[21.7 \%]}\end{array}$

\section{Figures}

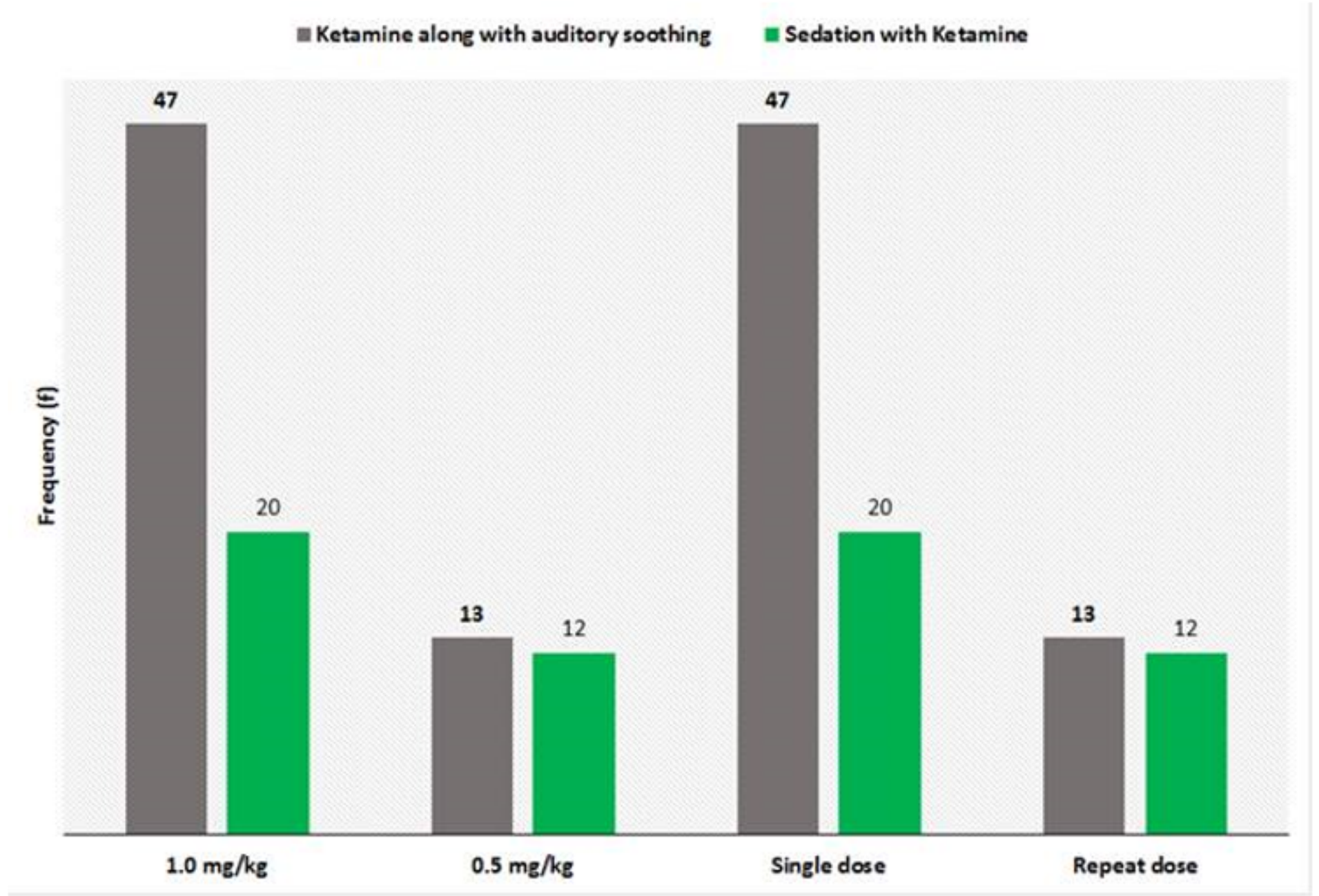

\section{Figure 1}

Frequency of both groups with Ketamine dose and Soothing effects 